\title{
En el centenario de Bertolt Brecht
}

Dentro de los muchos centenarios que se han celebrado a lo largo del año en curso, quisiera resaltar especialmente el de Bertolt Brecht. Brecht no sólo fue un prolífico poeta, narrador $\mathrm{y}$ autor dramático, sino también alguien que contribuyó enormemente a comprender los procesos culturales del siglo que está por finalizar. No es de extrañar, pues, su amistad y colaboración intelectual con otro importante teórico de la cultura contemporánea, Walter Benjamin. Pese a ello, en la mayoría de homenajes dedicados a su memoria, este aspecto tiende a ser infravalorado y hasta ignorado. Con poco disimulado revanchismo político, Mario Vargas Llosa - para citar un ejemploproclama el fracaso del teórico "marxista" y el triunfo del artista, del creador. Brecht habría querido superar el teatro burgués, pero el teatro burgués, a la larga, terminaría incorporando sus aportes sin llegar a transformarse sustancialmente $y$, mucho menos, a desaparecer. Creo que ésta es una forma bastante limitada de entender su estética teatral. Para aquilatarlo mejor, cabe hacer un breve recorrido por su trayectoria vital y sus ideas.

Bertolt Brecht nació en 1898 en el sur de Alemania. Provenía de una familia comerciante de clase media de instrucción poco notoria. Ese medio familiar, guiado más por el sentido común que por la "cultura", marcaría a Brecht: predominio de lo práctico sobre lo contemplativo, afinidad a la ciencia y la tecnología y desprecio por el culto esnobista de la alta cultura. Para Brecht, la palabra arte, pues, no debía separarse de su origen etimológico que lo emparenta con las artesanías, las artes manuales y el simple hacer. Por ello, contra la tradición estética idealista, privilegia Brecht el componente lúdico y práctico por encima del desinterés contemplativo. Se puede decir que su preocupación central a lo largo de su carrera es vencer la actitud puramente receptiva del espectador, abreviar la distancia que separa al espectador del escenario y, en cierta forma, romper los muros del teatro.

Brecht inició su carrera como director de Teatro poco después de terminada la Guerra. Sin embargo, después se involucró en el teatro obrero y en la actividad teatral dirigida hacia los núcleos progresistas de la intelectualidad y las clases medias. Con la subida de Hitler al poder, en 1933, tuvo que abandonar Alemania y exiliarse, primero en Dinamarca y luego en Estados Unidos. Aquí se mantuvo hasta la década de los cincuenta cuando, intimidado por la cacería de brujas desatada por el senador MacCarthy, se vio obligado a salir de ese país. Finalmente se asentó en Berlín Oriental donde obtuvo apoyo del Estado de la República Democrática Alemana para fundar su compañía teatral, la Berliner Ensemble.

La contribución de Brecht al lenguaje teatral ha dejado una marca comparable a la de Picasso en el terreno de la plástica. Aún así, casi siempre se lo considera fundamentalmente como un revolucionador de las técnicas de la actuación y el montaje teatrales, y se pasa por alto la originalidad y las profundas implicaciones que tiene su reflexión crítica para una teoría marxista del arte. Aunque Brecht distaba de ser un filósofo o un teórico del arte, pocos de sus contemporáneos revelaron su ca- 
pacidad de comprender el carácter del arte como institución y el carácter irremediablemente semiótico de la vida social. Para Brecht, los lenguajes no son únicamente modos de representación sino, por encima de todo, modalidades de acción.

Para Brecht, la vida tenía un carácter irremediablementc teatral. El teatro es una imitación de la vida porque la vida es una suerte de teatro. En el primer apartado de su "Pequeño órganon para el Teatro", Brecht postula: "El teatro consiste en la elaboración de copias vivientes de los sucesos tradicionalmente recibidos o imaginados entre los hom-

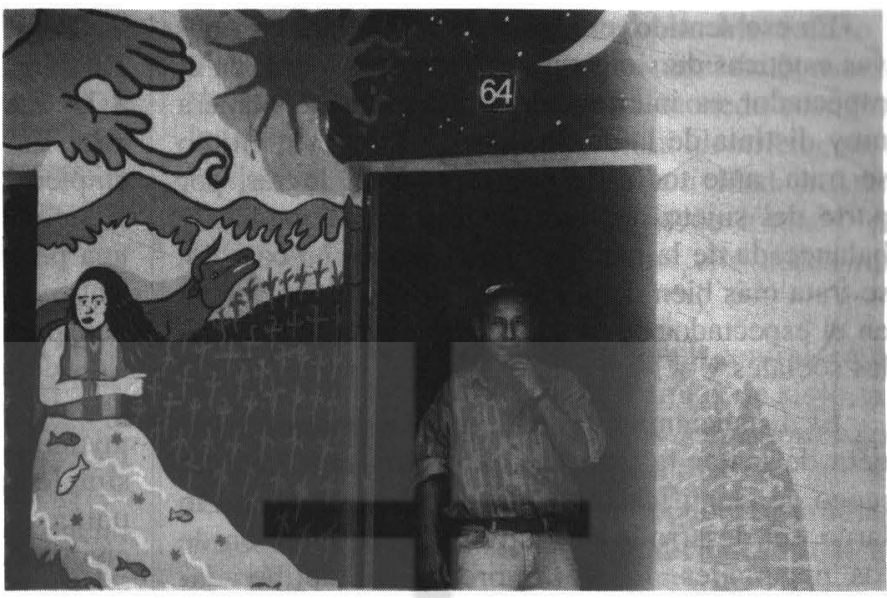
bres, y ello ciertamente para fines de esparcimiento". La elaboración de copias vivientes tiene más que un afán puramente didáctico o cognoscitivo. Es por ello que el placer que extraemos de la experiencia teatral tiene una base mucho más profunda.

La vida social consiste ante todo en representar una serie de roles. En nuestra vida práctica asumimos distintos papeles que hemos aprendido a representar a lo largo de nuestras vidas. En buena parte, el proceso de educación y de socialización de los niños consiste no sólo en aprender a actuar esos roles, sino todavía más a reconocernos en esos roles. Síntoma de nuestra madurez es que nos sintamos a nuestras anchas en esos roles, a identificarnos con ellos, es decir, a extraer una identidad coherente de la multiplicidad de posiciones a las que la vida nos obliga a enfrentarnos. Esa identidad coherente es en buena parte una construcción ficticia y no una verdadera superación de las contradicciones de nuestra vida real. Es, por lo tanto, un efecto ideológico que tiene por resultado nuestra aceptación acrítica del mundo tal cual es.

Estos efectos de identidad coherente están posibilitados por los momentos de retracción sobre nuestra interioridad así como por ficciones que nos dan las pautas para explorar nuestra interioridad y reelaborarla en una narración coherente. El arte, en general, y dentro de éste el teatro, es uno de estos mecanismos. Es una manera en que los espectadores pueden emplear sus momentos de ocio, pero que tiene efectos sobre su vida real. El principal efecto es apuntalar la ilusión de que mantenemos un control total sobre nuestras vidas. De esta forma, el teatro, en particular, y el arte, en

general, contribuyen a la reproducción social al compeler a los individuos a vivir una integridad ficticia y a permanecer inconcientes de los papeles contradictorios que el mundo que habitan les obliga a representar.

Tomarse la vida en serio, pues, implica de cierta manera asumir el libreto de la vida social sin titubear, sin interrogar. Por ello es que encontramos una paradójica crítica ingenua en el juego infantil, donde se experimente a invertir e intercambiar roles. Por ello es tan importante para Brecht combatir el efecto de 'identificación' propio del teatro tradicional y explotar formas de placer hasta entonces marginadas o abandonadas por éste.

Como alternativa al efecto de identificación, Brecht desarrolló la noción de efecto de distanciamiento [Verfremdungeffekt], la cual guarda estrecha relación con la de extrañamiento [Ostranenie] de los formalistas rusos, formulada por primera vez por Viktor Shklovsky. Ambos coinciden en que el arte con función mimética, independientemente de su contenido, tiene un efecto fundamentalmente conservador. La diferencia entre ambas teorizaciones radica, sin embargo, en que Brecht es mucho más consciente de sus implicaciones y efectos sociales.

Para Brecht, la identificación es mucho más que un problema de percepción de la realidad, es decir un problema de la relación de un sujeto con respecto a un mundo organizado socialmente. Es decir, menos un problema del sujeto en tanto que contemplador del mundo, que de éste en tanto actor. La empatía, efecto buscado por el teatro y la actuación tradicionales, tiene su correlato en el individuo moderno que vive su mundo de manera aproblemática. 
En ese sentido, el efecto de shock que las nuevas estéticas de vanguardias persiguen lograr en el espectador es interpretado por Brecht de manera muy distinta de la de Shklovsky. Para éste último se trata, ante todo, de una manera de lograr, por parte del sujeto, una percepción más completa y balanceada de la realidad. Para Brecht, en cambio, se trata más bien de una forma de crear conciencia en el espectador de la convencionalidad de los roles sociales y del lugar que ocupa en la sociedad.

El distanciamiento no es propiamente una manera de evitar la identificación, sino más bien un juego de identificación y shock del espectador a lo largo del desarrollo de la trama y en la acción de los personajes. El teatro brechtiano deliberadamente crea siluaciones que promueven una identificación emoliva del receptor con la acción y los personajes, sólo para romperla en momentos especílicos. Algunas de las técnicas brechtianas más conocidas son: la intervención de un 'narrador-intérprete' de los hechos que constantemente interrumpe la acción para interpelar a los espectadores, las técnicas de actuación que permiten a los actores ser capaces de salirse de su papel -a diferencia de la técnica teatral de Stanislavsky que busca la empatía total entre actor y papel-, y el empleo de música, canciones, cscenarios evidentemente 'lalsos'.

Brecht estaba consciente de lo limitado de la práctica teatral que proponía. Estaba plenamente consciente de que el arte en la socicdad moderna había sido relegado a la lunción de mero entretenimiento. Cuando descalifica superficialmente sus ideas se olvida que su estética teatral supone dos momentos para su pleno despliegue. El primero consiste en revolucionar la institución teatral desde dentro; en romper con la pasividad del espectador. Para ello se debe tener en cuenta el espacio que la sociedad burguesa confiere a esa práctica arlística. El teatro es, pues, un aparato o, dicho en términos más modernos, una institución. La actividad arlística no puede evaluarse exclusivamente en una apreciación de los textos artísticos. Se hace imperativa una consideración de las funciones sociales que esa práctica artística cumple. Es a partir de un examen de éstas últimas que Brecht propuso su nueva concepción del teatro. En ese sentido están la serie de técnicas dramálicas que rompen con la ilusión de autonomía de la experiencia estética. Ese es el aspecto más difundido, conocido y, hoy en día, atacado de la propuesta estética de Brecht.
Pero esta propuesta brechtiana suponía un segundo momento: romper el cerco de la autonomía a la que la sociedad burguesa ha condenado al arte. Es decir, a la función de esparcimiento, al empleo 'libre' del ocio. Esto sólo se puede lograr si se es capaz de conectar el trabajo artístico con una praxis política emancipadora. Así, este nuevo teatro debía correr junto a una nueva práctica política participativa donde tuviera lugar una discusión de temas de aspectos de interés público pero que incorporase la presentación estética de los mismos. Este componente estético no consistía simplemente en ilustrar amenamente contenidos políticos previamente definidos. Suponía un ejercicio en el cual todos los involucrados debían descubrir esos problemas intercambiando roles, de tal forma que las posiciones jerárquicas y subordinadas se volvieran, al menos durante este juego, intercambiables.

Ahora bien, este planteamiento constituía, cuando menos en apariencia, un reto al principio del centralismo democrático adoptado por la ortodoxia marxista-leninista. Sin embargo, por una ironía de la historia, los conflictos de Brecht con la ortodoxia cultural del movimicnto comunista vendrían por otras razones. Básicamente, por la actitud receptiva - si bien crítica- de Brecht hacia las estéticas de vanguardia. No hay que olvidar que éstas habían sido condenadas por la eslélica oficial y dicha condena había sido legitimada por Georg Lukács, una de las mentes más brillantes de este siglo pero que por entonces había asumido el penoso papel de estela oficial del partido y de Gran Inquisidor de la vanguardia artística progresista.

La historia iría cerrando las posibilidades de realización del segundo momento del proyecto brechtiano. Instaurado el nazismo, debió exiliarse primero en Dinamarca y luego en Estados Unidos. Al término de la conflagración mundial, debió sufrir en este país el clima de intolerancia de la Gucrra Fría. Obligado a declarar en el Congreso ante el comité que investigaba actividades nortcamericanas, Brecht prefirió trasladarse a Suiza. Luego de muchas reticencias, acabó aceptando la oferta de las autoridades culturales de la República Democrática Alcmana de instalarse en ese país.

Brecht luvo que retractarse de sus sueños más atrevidos y plegarse a la política cultural oficial de la llamada República Democrática Alemana, uno de los regímenes más siniestros tras la cortina de 
hierro. Las expectativas de Brecht de poder revolucionar la vida a través del teatro no se cumplieron tampoco dentro del "socialismo real". Debió integrarse a su aparato cultural para sobrevivir. Su trabajo con el Berliner Ensemble implicó, irremediablemente, la asimilación de sus innovadoras técnicas dramáticas a la institución teatral tradicional.

La frustración de la expectativas de Brecht por las circunstancias de la vida y la historia, no implican empero la total invalidación de sus ideas estéticas. Tampoco cabe caer en el extremo opuesto de querer hacerlas valer sin la correspondiente crítica. Su análisis de la institución artística de su tiempo no deja de ser lúcido. Tampoco resulta totalmente inválida su percepción de la teatralidad de la vida social, inluición que, dicho sea de paso, han desarrollado posteriormente sociólogos como Erwin Goffmann. Igualmente sugerente resulta la aspiración de Brecht de hacer del espectador un partícipe, un coautor del trabajo artístico.

Sin embargo, una crítica de la cultura contemporánea debe enfrentarse a un problema que la propuesta de Brecht no contempla. Me refioro u que tanto el arte culto como el arte de consumo masivo han terminado por hacer moneda corriente los dispositivos que rompen con la identificación y la ilusión de transparencia. La actividad artísticu moderna tolera una enorme dosis de ironía y de recursos distanciadores sin ser por ello necesaritymente crítico.

Brecht fue, además de un autor central en la gran renovación artística de principios de siglo, un hombre de teatro con sinceras preocupaciones políticas. Sin tener formación filosófica, sin ser un pensador sistemático ni mucho menos un erudito, nos legó un cuerpo de ideas e intuiciones estéticas que todavía resultan provocadoras para comprender la compleja dinámica de evolución de la institución artística y del campo cultural en las sociedades avanzadas. Quizá por ello es válido señarlo —haciendo paráfrasis de su celebrado poemacomo uno de los indispensables del siglo XX.

Ricardo Roque Baldovinos 